\title{
Albumin-to-alkaline phosphatase ratio serves as a prognostic indicator in unresectable pancreatic ductal adenocarcinoma: a propensity score matching analysis
}

Ke Zhang

Fudan University Shanghai Cancer Center

Shu Dong

Fudan University Shanghai Cancer Center

Yan Hua Jing

Fudan University Shanghai Cancer Center Hui Feng Gao

Fudan University Shanghai Cancer Center Lian Yu Chen

Fudan University Shanghai Cancer Center

\section{Yong Qiang Hua}

Fudan University Shanghai Cancer Center

Hao Chen

Fudan University Shanghai Cancer Center

Zhen Chen ( $\nabla$ zchenzl@fudan.edu.cn )

Fudan University Shanghai Cancer Center https://orcid.org/0000-0002-4502-0801

Research article

Keywords: pancreatic ductal adenocarcinoma, albumin-to-alkaline phosphatase ratio, propensity score matching, overall survival, prognostic marker

Posted Date: April 7th, 2020

DOI: https://doi.org/10.21203/rs.3.rs-20224/v1

License: (c) (1) This work is licensed under a Creative Commons Attribution 4.0 International License. Read Full License 
Version of Record: A version of this preprint was published at BMC Cancer on June 9th, 2020. See the published version at https://doi.org/10.1186/s12885-020-07023-9. 


\section{Abstract}

Background Recent evidence suggests that albumin-to-Alkaline Phosphatase Ratio (AAPR) functions as a novel prognostic marker in several malignancies. However, whether it can predict the prognosis of unresectable pancreatic ductal adenocarcinoma (PDAC) remains unclear. Herein, we seek to investigate this possibility by a propensity score matching (PSM) analysis.

Methods This was a retrospective cohort study in which 419 patients diagnosed with unresectable PDAC and receiving chemotherapy were recruited. Patients were stratified based on the cutoff value of AAPR. The PSM analysis was performed to identify 156 well-balanced patients in each group for overall survival (OS) comparison and subgroup analysis. Univariate and multivariate analyses were carried out to examine the potential of AAPR to indicate the prognosis of unresectable PDAC. The prediction performance of conventional model and combined model including AAPR was compared using the Akaike Information Criterion (AIC) and concordance index (C-index).

Results We identified an AAPR of 0.4 to be the optimal cutoff for OS prediction. Patients with AAPR $\leq 0.4$ had significantly shorter OS compared with patients with AAPR>0.4 (6.4 versus 9.3 months; $P<0.001$ ). Based on the PSM cohort and entire cohort, multivariate Cox analysis revealed that high pretreatment for AAPR was an independent marker predicting favorable survival in unresectable PDAC (hazard ratio, $0.556 ; 95 \%$ confidence interval, 0.408 to $0.757 ; P<0.001)$. Significant differences in OS were observed in all subgroups except for the group of patients age $\leq 60$. Combined prognostic model including AAPR had lower AIC and higher C-index than conventional prognostic model.

Conclusions Pretreatment AAPR servers as an independent prognostic indicator for patients with unresectable PDAC. Inclusion of AAPR improved the prediction performance of conventional prognostic model, potentially helping clinicians to identify patients at high risk and guide individualized treatment.

\section{Background}

Pancreatic ductal adenocarcinoma (PDAC) is a fatal disease and the fourth leading cause of cancerrelated death worldwide with a 5-year survival rate of $8 \%$ [1]. In China, PDAC is ranked sixth among cancer-related deaths and ninth among the most prevalent cancers [2]. Currently there are not effective treatment for PDAC. surgical resection remains the only curative treatment. However, the overall management of PDAC patients is far from being satisfactory, since approximately $80 \%$ of patients are diagnosed at advanced and unresectable stages and received systemic chemotherapy[3][4]. Gemcitabinebased combination regimen or the fluorouracil, leucovorin, irinotecan, and oxaliplatin (FOLFIRINOX) are currently the most recommended in cases of advanced stage PDAC [5][6][7]. Unfortunately, tumor biology of PDAC causes resistance to systemic therapy, thereby leading to poor prognosis. Notably, patients with similar PDAC disease conditions sometimes have different outcomes. Therefore, it is crucial to identify a prognostic marker that can predict survival and hence guide clinical decisions for patients with unresectable PDAC. 
Serum albumin (ALB) is synthesized in the liver and is the most abundant protein in plasma. And this may explain why it is usually included in standard blood tests to assess hepatic function. Also, it performs various roles, ranging from regulating oncotic pressure to scavenging reactive oxygen species. Recent evidence has shown that ALB is an accurate biomarker reflecting underlying host systemic inflammatory responses[8]. Besides, alkaline phosphatase (ALP) is enriched in kidney, bile duct, and liver [9]. Studies have shown that serum ALP is a useful marker of tumor growth and metastasis[10][11][12].

Accordingly, albumin-to-alkaline phosphatase ratio (AAPR) is postulated to be a prognostic indicator in hepatocellular carcinoma [13]. So far, its prognostic performance has been studied for multiple malignancies such as non-small-cell lung cancer[14], metastatic nasopharyngeal cancer [15], cholangiocarcinoma [16], upper tract urothelial carcinoma[17], renal cell carcinoma[18], and cervical cancer[19]. Notably, Pu et al. [20] concluded that preoperative AAPR is an independent factor that determines PDAC progression after curative resection. However, little is known about ability of AAPR to reflect the clinical outcomes of unresectable PDAC, which accounts for the majority of the PDAC.

Taking this need into consideration, we conducted a retrospective cohort study and performed propensity score-matching (PSM) analysis to investigate the prognostic significance of pretreatment AAPR in unresectable PDAC treated with chemotherapy.

\section{Patients And Methods}

Study design and patient characteristics

Prior to this study, approval was obtained from the Ethics Committee of Fudan University Shanghai Cancer Center. All participants were enrolled retrospectively and provided written informed consent in line with our institutional guidelines.

This was a single-center retrospective cohort study. A total of 419 patients pathologically diagnosed with unresectable PDAC and treated at Fudan University Shanghai Cancer Center between January 1st, 2011 and December 31st, 2015 were enrolled. During participant enrollment, the following criteria was employed: 1) patients diagnosed with pancreatic adenocarcinoma histologically or cytologically; 2) subjects who had metastasized and locally advanced disease or defined as stage III or IV in line with the American Joint Committee on Cancer, 8th edition (Chicago, IL, USA) [21]; 3) patients who had no history of malignant disease prior to treatment. Participants meeting the following criteria were precluded from the study: 1) patients who had untreated obstructive jaundice, acute infectious diseases, or hematological diseases; 2) patients who lacked complete clinicopathological and follow-up data.

Data on conventional clinicopathological variables, such as demographic data, tumor location, stage, carbohydrate antigen 19-9 (CA19-9), ALB, and ALP, were retrieved. We performed all biochemical tests prior to treatment and diagnosis. This information was retrieved from electronic record system at our center. 
The primary outcome of this study was overall survival (OS), which was defined as the duration from diagnosis to date of last follow-up or death due to any cause. Patients follow-up information was obtained via medical records or telephone interviews. The last follow-up date was December 31st, 2017.

Albumin-to-alkaline phosphatase ratio (AAPR)

Pretreatment AAPR was defined as a serum albumin/serum alkaline phosphatase ratio. The median AAPR for the whole cohort was 0.46 (range, 0.05 to 1.60). We further used the X-tile 3.6.1 software (Yale University, New Haven, CT) [22] to determine the optimal cutoff point of AAPR for OS prediction in the entire cohort. Consequently, all patients were stratified into the low AAPR $(\leq 0.4)$ group and the high AAPR (>0.4) group for subsequent analyses.

We then compared the baseline patient characteristics of low and high AAPR groups. Moreover, subgroup analyses were conducted according to patients' age, sex, location, tumor stage, and CA19-9 level.

Statistical analysis

Pearson's chi-square test and Fisher's exact test were utilized to compare baseline characteristics between groups. The survival estimates of OS were determined using the Kaplan-Meier method, and group differences were analyzed using log-rank test. Univariate and multivariate analyses were carried out using the Cox proportional hazards regression model to evaluate the prognostic effect of variables and estimate the hazard ratio (HR) with a 95\% confidence interval (Cl).

Propensity score matching (PSM) analysis was applied to reduce bias by equating the two groups based on the following variables: age, sex, location, tumor stage, and CA19-9 level. In the PSM analysis, the confounders must not be influenced by factors of AAPR, indicating that ALB and ALP were not included for balance[23]. The PSM analysis was performed using the nearest-neighbor 1:1 matching method with a caliper width of 0.02 of the pooled standard deviation of the logit of the propensity score.

The prediction performance of conventional model and combined model including AAPR was compared using the Akaike Information Criterion (AIC)[24] and the concordance index (C-index)[25].

All tests were two-sided and were carried out with IBM SPSS 24.0 software (IBM SPSS Statistics, Version 24.0. Armonk, NY) and R software, version 3.5.0 (https://www.r-project.org/). P-value $<0.05$ was considered statistically significant.

\section{Results}

\section{Patient characteristics}

This respective study covered 419 patients with unresectable PDAC. These patients were follow-up for a median period of eight months (range, 1 to 42 months). Six patients were alive at the last follow-up. All subjects received gemcitabine-based palliative chemotherapy (gemcitabine monotherapy or combination 
regimens, as exemplified by gemcitabine plus albumin-bound paclitaxel, gemcitabine plus capecitabine, and gemcitabine plus oxaliplatin/ cisplatin). The baseline clinicopathologic features of the patients according to the APPR level before and after PSM are presented in Table 1. In the unmatched cohort, patients with low APPR levels were associated with a more advanced tumor stage and higher CA19-9 level. After PSM, there were 156 matched pairs in two groups. Among these patients, 195 (62.5\%) were male and 117 (37.5\%) female, with a median age of 62 years (range, 25 to 83 years). Also, $50(16.0 \%)$ patients presented with stage III of the disease, whereas the remaining $262(84.0 \%)$ presented with stage IV. Baseline characteristics in the low and high AAPR groups were well matched after PSM (Table 1, Fig. 1). 
Baseline patient information and clinical features

\begin{tabular}{|c|c|c|c|c|c|c|c|c|}
\hline \multirow[t]{2}{*}{ Characteristics } & \multicolumn{4}{|c|}{ Before PSM } & \multicolumn{4}{|c|}{ After PSM } \\
\hline & $\begin{array}{l}\text { Total } \\
(\mathrm{N}= \\
419)\end{array}$ & $\begin{array}{l}\text { AAPR } \leq \\
0.4(N= \\
173)\end{array}$ & $\begin{array}{l}\text { AAPR > } \\
0.4(N= \\
246)\end{array}$ & $\begin{array}{l}\mathrm{P} \text { - } \\
\text { value }\end{array}$ & $\begin{array}{l}\text { Total } \\
(\mathrm{N}= \\
312)\end{array}$ & $\begin{array}{l}\text { AAPR } \leq \\
0.4(\mathrm{~N}= \\
156)\end{array}$ & $\begin{array}{l}\text { AAPR > } \\
0.4(\mathrm{~N}= \\
156)\end{array}$ & $\begin{array}{l}\mathrm{P} \text { - } \\
\text { value }\end{array}$ \\
\hline \multicolumn{9}{|l|}{ Age } \\
\hline$\leq 60$ & $\begin{array}{l}200 \\
(47.7)\end{array}$ & $78(45.1)$ & $\begin{array}{l}122 \\
(49.6)\end{array}$ & 0.373 & $\begin{array}{l}136 \\
(43.6)\end{array}$ & $\begin{array}{l}72 \\
(46.2)\end{array}$ & $\begin{array}{l}64 \\
(41.0)\end{array}$ & 0.424 \\
\hline$>60$ & $\begin{array}{l}219 \\
(52.3)\end{array}$ & $95(54.9)$ & $\begin{array}{l}124 \\
(50.4)\end{array}$ & & $\begin{array}{l}176 \\
(56.4)\end{array}$ & $\begin{array}{l}84 \\
(53.8)\end{array}$ & $\begin{array}{l}92 \\
(59.0)\end{array}$ & \\
\hline \multicolumn{9}{|l|}{ Sex } \\
\hline Male & $\begin{array}{l}269 \\
(64.2)\end{array}$ & $\begin{array}{l}108 \\
(62.4)\end{array}$ & $\begin{array}{l}161 \\
(65.4)\end{array}$ & 0.536 & $\begin{array}{l}195 \\
(62.5)\end{array}$ & $\begin{array}{l}99 \\
(63.5)\end{array}$ & $\begin{array}{l}96 \\
(61.5)\end{array}$ & 0.815 \\
\hline Female & $\begin{array}{l}150 \\
(35.8)\end{array}$ & 65 (37.6) & 85 (34.6) & & $\begin{array}{l}117 \\
(37.5)\end{array}$ & $\begin{array}{l}57 \\
(36.5)\end{array}$ & $\begin{array}{l}60 \\
(38.5)\end{array}$ & \\
\hline \multicolumn{9}{|l|}{$\begin{array}{l}\text { Tumor } \\
\text { location }\end{array}$} \\
\hline Head & $\begin{array}{l}177 \\
(42.2)\end{array}$ & $83(48.0)$ & $94(38.2)$ & 0.056 & $\begin{array}{l}137 \\
(43.9)\end{array}$ & $\begin{array}{l}66 \\
(42.3)\end{array}$ & $\begin{array}{l}71 \\
(45.5)\end{array}$ & 0.648 \\
\hline Body/tail & $\begin{array}{l}242 \\
(57.8)\end{array}$ & $90(52.0)$ & $\begin{array}{l}152 \\
(61.8)\end{array}$ & & $\begin{array}{l}175 \\
(56.1)\end{array}$ & $\begin{array}{l}90 \\
(57.7)\end{array}$ & $\begin{array}{l}85 \\
(54.5)\end{array}$ & \\
\hline \multicolumn{9}{|l|}{ Stage } \\
\hline III & $\begin{array}{l}83 \\
(19.8)\end{array}$ & $22(12.7)$ & $61(24.8)$ & 0.003 & $\begin{array}{l}50 \\
(16.0)\end{array}$ & $\begin{array}{l}22 \\
(14.1)\end{array}$ & $\begin{array}{l}28 \\
(17.9)\end{array}$ & 0.441 \\
\hline IV & $\begin{array}{l}336 \\
(80.2)\end{array}$ & $\begin{array}{l}151 \\
(87.3)\end{array}$ & $\begin{array}{l}185 \\
(75.2)\end{array}$ & & $\begin{array}{l}262 \\
(84.0)\end{array}$ & $\begin{array}{l}134 \\
(85.9)\end{array}$ & $\begin{array}{l}128 \\
(82.1)\end{array}$ & \\
\hline \multicolumn{9}{|l|}{$\begin{array}{l}\text { CA19-9 } \\
(\mathrm{U} / \mathrm{mL})\end{array}$} \\
\hline$\leq 1000$ & $\begin{array}{l}247 \\
(58.9)\end{array}$ & $85(49.1)$ & $\begin{array}{l}162 \\
(65.9)\end{array}$ & 0.001 & $\begin{array}{l}170 \\
(54.5)\end{array}$ & $\begin{array}{l}85 \\
(54.5)\end{array}$ & $\begin{array}{l}85 \\
(54.5)\end{array}$ & 1.000 \\
\hline$>1000$ & $\begin{array}{l}172 \\
(41.1)\end{array}$ & $88(50.9)$ & $84(34.1)$ & & $\begin{array}{l}142 \\
(45.5)\end{array}$ & $\begin{array}{l}71 \\
(45.5)\end{array}$ & $\begin{array}{l}71 \\
(45.5)\end{array}$ & \\
\hline \multicolumn{9}{|l|}{ ALB (g/L) } \\
\hline
\end{tabular}




\begin{tabular}{|c|c|c|c|c|c|c|c|c|}
\hline \multirow[t]{2}{*}{ Characteristics } & \multicolumn{4}{|c|}{ Before PSM } & \multicolumn{4}{|c|}{ After PSM } \\
\hline & $\begin{array}{l}\text { Total } \\
(\mathrm{N}= \\
419)\end{array}$ & $\begin{array}{l}\text { AAPR } \leq \\
0.4(N= \\
173)\end{array}$ & $\begin{array}{l}\text { AAPR }> \\
0.4(\mathrm{~N}= \\
246)\end{array}$ & $\begin{array}{l}\text { P- } \\
\text { value }\end{array}$ & $\begin{array}{l}\text { Total } \\
(\mathrm{N}= \\
312)\end{array}$ & $\begin{array}{l}\text { AAPR } \leq \\
0.4(\mathrm{~N}= \\
156)\end{array}$ & $\begin{array}{l}\text { AAPR > } \\
0.4(\mathrm{~N}= \\
156)\end{array}$ & $\begin{array}{l}\mathrm{P} \text { - } \\
\text { value }\end{array}$ \\
\hline$\leq 35$ & $\begin{array}{l}26 \\
(6.2)\end{array}$ & $20(11.6)$ & $6(2.4)$ & $\begin{array}{l}<.001 \\
0.00\end{array}$ & $\begin{array}{l}20 \\
(6.4)\end{array}$ & $\begin{array}{l}17 \\
(10.9)\end{array}$ & $3(1.9)$ & 0.002 \\
\hline$>35$ & $\begin{array}{l}393 \\
(93.8)\end{array}$ & $\begin{array}{l}153 \\
(88.4)\end{array}$ & $\begin{array}{l}240 \\
(97.6)\end{array}$ & & $\begin{array}{l}292 \\
(93.6)\end{array}$ & $\begin{array}{l}139 \\
(89.1)\end{array}$ & $\begin{array}{l}153 \\
(98.1)\end{array}$ & \\
\hline \multicolumn{9}{|l|}{ ALP (U/L) } \\
\hline$\leq 125$ & $\begin{array}{l}296 \\
(70.6)\end{array}$ & $51(29.5)$ & $\begin{array}{l}245 \\
(99.6)\end{array}$ & $\begin{array}{l}<.001 \\
0.00\end{array}$ & $\begin{array}{l}204 \\
(65.4)\end{array}$ & $\begin{array}{l}49 \\
(31.4)\end{array}$ & $\begin{array}{l}155 \\
(99.4)\end{array}$ & $\begin{array}{l}<.001 \\
0.00\end{array}$ \\
\hline$>125$ & $\begin{array}{l}123 \\
(29.4)\end{array}$ & $\begin{array}{l}122 \\
(70.5)\end{array}$ & $1(0.4)$ & & $\begin{array}{l}108 \\
(34.6)\end{array}$ & $\begin{array}{l}107 \\
(68.6)\end{array}$ & $1(0.6)$ & \\
\hline $\begin{array}{l}\text { Abbreviations: } \\
\text { HR, hazard ratio } \\
\text { matching; NA, } n\end{array}$ & $\begin{array}{l}\text { P, alkali } \\
\text { Cl, confi } \\
\text { t availal }\end{array}$ & $\begin{array}{l}\text { phosphat } \\
\text { ice interva }\end{array}$ & $\begin{array}{l}\text { e; ALB, al } \\
\text { CA19-9, c }\end{array}$ & $\begin{array}{l}\text { in; AA } \\
\text { ohydra }\end{array}$ & $\begin{array}{l}\text { R, albur } \\
\text { antiger }\end{array}$ & $\begin{array}{l}\text { to alkalir } \\
9-9 ; \text { PSı }\end{array}$ & $\begin{array}{l}\text { phosphat } \\
\text { propensit }\end{array}$ & $\begin{array}{l}\text { e ratio; } \\
\text { core }\end{array}$ \\
\hline
\end{tabular}

Association between AAPR and clinicopathologic characteristics in unresectable PDAC

The clinicopathologic features of high and low AAPR groups are summarized in Table 1. Subjects with high AAPR values had significantly lower ratios of stage IV of the disease $(P=0.003)$, high CA19-9 level $(P=0.001)$, hypoalbuminemia $(P<0.001)$, and elevated ALP $(P<0.001)$ compared with those patients with high AAPR level.

Prognostic significance of AAPR in unresectable PDAC

In the entire cohort, the Kaplan-Meier analysis suggested that low AAPR positively correlated with poor survival $(p<0.001$, Fig. $2 A)$. The median OS of subjects with AAPR $\leq 0.40$ and AAPR $>0.40$ was 6.4 months ( $95 \% \mathrm{Cl}, 5.4$ to 7.4$)$ and 9.3 months (95\% Cl: 7.9-10.6), respectively. Univariate Cox analysis revealed that the tumor stage, CA19-9 level, ALP, and AAPR were strongly linked to OS (Table 2).

Furthermore, it was uncovered that AAPR was an independent prognostic factor of OS $(\mathrm{HR}, 0.556 ; 95 \% \mathrm{Cl}$, 0.408 to $0.757 ; \mathrm{P}<0.001$; Table 3 ). 
Table 2

Univariate Cox regression analysis of clinical parameters for OS

\begin{tabular}{|c|c|c|c|c|}
\hline \multirow[t]{2}{*}{ Characteristics } & \multicolumn{2}{|l|}{ Before PSM } & \multicolumn{2}{|l|}{ After PSM } \\
\hline & $\mathrm{HR}(95 \% \mathrm{Cl})$ & $\begin{array}{l}\text { P- } \\
\text { value }\end{array}$ & $\mathrm{HR}(95 \% \mathrm{Cl})$ & $\begin{array}{l}\text { P- } \\
\text { value }\end{array}$ \\
\hline Age, years ( $\leq 60$ vs. $>60$ ) & $\begin{array}{l}1.064(0.877- \\
1.292)\end{array}$ & 0.528 & $\begin{array}{l}0.995(0.794- \\
1.248)\end{array}$ & 0.968 \\
\hline Sex (male vs. female) & $\begin{array}{l}1.124(0.919- \\
1.376)\end{array}$ & 0.254 & $\begin{array}{l}1.157(0.918- \\
1.458)\end{array}$ & 0.218 \\
\hline $\begin{array}{l}\text { Tumor location (head vs. } \\
\text { body/tail) }\end{array}$ & $\begin{array}{l}0.872(0.717- \\
1.062)\end{array}$ & 0.872 & $\begin{array}{l}1.036(0.825- \\
1.302)\end{array}$ & 0.760 \\
\hline Stage (III vs. IV) & $\begin{array}{l}1.643(1.278- \\
2.113)\end{array}$ & $<0.001$ & $\begin{array}{l}1.438(1.046- \\
1.976)\end{array}$ & 0.025 \\
\hline CA19-9, U/mL ( $\leq 1000$ vs. >1000) & $1.472(1.204-1.800)$ & $<0.001$ & $\begin{array}{l}1.416(1.123- \\
1.785)\end{array}$ & 0.003 \\
\hline ALB, g/L ( $\leq 35$ vs. >35) & $\begin{array}{l}0.670(0.446- \\
1.005)\end{array}$ & 0.053 & $\begin{array}{l}0.713(0.448- \\
1.136)\end{array}$ & 0.155 \\
\hline ALP, U/L ( $\leq 125$ vs. >125) & $\begin{array}{l}1.299(1.049- \\
1.608)\end{array}$ & 0.016 & $\begin{array}{l}1.210(0.955- \\
1.533)\end{array}$ & 0.114 \\
\hline $\operatorname{AAPR}(\leq 0.4$ vs. $>0.4)$ & $\begin{array}{l}0.624(0.512- \\
0.761)\end{array}$ & $<.001$ & $\begin{array}{l}0.599(0.477- \\
0.753)\end{array}$ & $<0.001$ \\
\hline \multicolumn{5}{|c|}{$\begin{array}{l}\text { Abbreviations: AAPR, albumin to alkaline phosphatase ratio; ALB, albumin; ALP, alkaline phosphatase; } \\
\text { CA19-9, carbohydrate antigen } 19-9 ; \mathrm{Cl} \text {, confidence interval; } \mathrm{HR} \text {, hazard ratio; PSM, propensity score } \\
\text { matching. }\end{array}$} \\
\hline
\end{tabular}


Table 3

Multivariate Cox regression analysis of clinical parameters for OS

\begin{tabular}{|c|c|c|c|c|}
\hline \multirow[t]{2}{*}{ Characteristics } & \multicolumn{2}{|l|}{ Before PSM } & \multicolumn{2}{|l|}{ After PSM } \\
\hline & $\mathrm{HR}(95 \% \mathrm{Cl})$ & $\begin{array}{l}\text { P- } \\
\text { value }\end{array}$ & $\mathrm{HR}(95 \% \mathrm{Cl})$ & P-value \\
\hline Stage (III vs. IV) & $\begin{array}{l}1.372(1.053- \\
1.787)\end{array}$ & 0.019 & $\begin{array}{l}1.200(0.865- \\
1.666)\end{array}$ & 0.274 \\
\hline $\begin{array}{l}\text { CA19-9, U/mL ( } \leq 1000 \text { vs. } \\
>1000)\end{array}$ & $\begin{array}{l}1.296(1.053- \\
1.594)\end{array}$ & 0.014 & $\begin{array}{l}1.356(1.071- \\
1.717)\end{array}$ & 0.011 \\
\hline ALP, U/L ( $\leq 125$ vs. $>125)$ & $\begin{array}{l}0.743(0.537- \\
1.028)\end{array}$ & 0.073 & NA & NA \\
\hline $\operatorname{AAPR}(\leq 0.4$ vs. $>0.4)$ & $\begin{array}{l}0.556(0.408- \\
0.757)\end{array}$ & $<.001$ & $\begin{array}{l}0.619(0.491- \\
0.779)\end{array}$ & $<0.001$ \\
\hline \multicolumn{5}{|c|}{$\begin{array}{l}\text { Abbreviations: NA, not available; ALP, alkaline phosphatase; CA19-9, carbohydrate antigen } 19-9 \text {; } \\
\text { hazard ratio; Cl, confidence interval; HR, PSM, propensity score matching; AAPR, albumin to alkaline } \\
\text { phosphatase ratio. }\end{array}$} \\
\hline
\end{tabular}

In the PSM cohort, the KM analysis showed that patients with AAPR $\leq 0.40$ had shorter OS compared with patients with AAPR $>0.40$ ( $P<0.001$, Fig. 2B). The median OS of high and low AAPR groups was 10.4 months ( $95 \% \mathrm{Cl}, 8.6$ to 12.2 ), and 6.7 months ( $95 \% \mathrm{Cl}, 5.9$ to 7.5 ), respectively. Results of the univariate Cox analysis suggested that the tumor stage, CA19-9 level, and AAPR had prognostic value for survival. High AAPR was significantly related to longer OS (HR, $0.599 ; 95 \% \mathrm{Cl}, 0.477$ to $0.753 ; \mathrm{P}<0.001$; Table 2). Finally, the multivariate Cox analysis demonstrated that AAPR might be an independent prognostic indicator for OS (HR, 0.619; $95 \% \mathrm{Cl}, 0.491$ to $0.779 ; \mathrm{P}<0.001$; Table 3 ).

Subgroup analysis

We performed subgroup survival analyses to further assess the prognostic performance of AAPR in unresectable PDAC patients. This was done by grouping patients according to baseline characteristics, such as sex, age, tumor location, tumor stage, and CA19-9 level. We found that pretreatment AAPR significantly correlated with OS in all subgroups except for the group of age $\leq 60$ (Fig. 3).

Prognostic models evaluation

Based on the multivariate Cox analysis, the conventional prognostic model included tumor stage, CA19-9 level. The combined model was constructed based on the conventional model and AAPR. These two prognostic models were evaluated by AIC and C-index (Table 4). The model with lower AIC was the combined model including AAPR in both total cohort and PSM cohort. In addition, the model with higher C-index for both total cohort and PSM cohort was also the combined model with AAPR included. 
Table 4

Prognostic model comparison for the conventional model and combined model including AAPR

\begin{tabular}{|lll|}
\hline & Total cohort & PSM cohort \\
\hline Conventional model (AIC) & 4153.24 & 2921.76 \\
\hline Combined model (AIC) & 4150.64 & 2914.30 \\
\hline Conventional model [C-index (95\% CI)] & $0.616(0.585-0.647)$ & $0.595(0.553-0.632)$ \\
\hline Combined model [C-index (95\% Cl)] & $0.626(0.595-0.657)$ & $0.619(0.584-0.654)$ \\
\hline $\begin{array}{l}\text { Abbreviations: AIC, Akaike Information; Cl, confidence interval; C-index, concordance index; PSM, } \\
\text { propensity score matching. }\end{array}$ & \\
\hline
\end{tabular}

\section{Discussion}

In the current study, we constructed AAPR, an easily available index comprised of serum ALB and ALP level. We further investigated its prognostic significance in unresectable PDAC patients. Analysis of the patient characteristics showed that low AAPR was closely associated with more advanced stage and higher CA19-9 level. PSM analysis was performed to generate well-balanced patients in low and high AAPR groups for survival comparison. Univariate and multivariate Cox analysis indicated that APPR served as an independent prognostic predictor for OS in both entire cohort and PSM cohort. In addition, we found that AAPR could be used in most subgroups except for the group of age $\leq 60$. More importantly, inclusion of AAPR improved the prediction performance of conventional prognostic model.

To our best knowledge, Chan et al. [26] were the first to report that AAPR can act as a novel prognostic index for patients with hepatocellular carcinoma patients underwent curative surgery. Since then, numerous studies have looked into the prognostic performance of AAPR for various malignancies, such as metastatic nasopharyngeal cancer [15], non-small-cell lung cancer[14], cholangiocarcinoma[16], upper tract urothelial carcinoma[17], renal cell carcinoma [18], and cervical cancer[19]. Particularly, Pu et al. [20] examined the AAPR in patients receiving surgery for PDAC and concluded that preoperative AAPR could independently predict postoperative OS in PDAC patients. Consistently, our data reveled that low AAPR correlated with poor OS. Also, we revealed that AAPR might function as an independent prognostic predictor in unresectable PDAC patients. In the subgroup analyses, the outcome of survival consistently favored the high AAPR group across most subgroups except in the group of age $\leq 60$. Despite the findings not being significant, the trend in the group of age $\leq 60$ was consistent with other groups.

Cancer is marked by rapid tumor cell proliferation and invasion[27], which may lead to various metabolic changes, such as enhanced production of some serum proteins, cytokines, and hormones. Thus, serum ALB and ALP might reflect tumor progression, and can, therefore, be used to predict clinical outcomes. The following mechanisms may explain the biological relationship between AAPR and prognosis of unresectable PDAC. 
As the most abundant protein in serum, ALB is the primary determinant of plasma oncotic pressure. Besides, ALB offers storages and conveyors for many exogenous and endogenous substances[28]. Serum ALB levels reflect the nutritional status and liver function in humans. It is widely recognized that inflammation, tumor microenvironment, and their interaction play critical roles in tumor progression[29]. Studies have shown that ALB can modulate the inflammatory reaction by binding prostaglandins, lipopolysaccharide, and reactive oxygen species [30]. Moreover, ALB has been found to suppress the cell cycle and progression of hepatocellular carcinoma[31][32]. Recent lines of evidence have identified ALB as an independent prognostic indicator in various malignant tumors, including lung[33], breast[34], and gastric cancers[35].

As a phosphate monoester hydrolase, ALP promotes the hydrolysis and transfer of phosphate groups in alkaline conditions[36]; therefore, it is regularly examined to evaluate liver function in clinical practice. Increasing evidence has shown that ALP can serve as a tumor-associated antigen and biomarker of cancer cell proliferation [11][37]. On the contrary, a reduction of ALP activity induces cell death, mesenchymal-to-epithelial transition, and suppresses cell migration[38]. Besides, ALP activity level is commonly used to predict bone metastasis in various types of cancer[39][40]. In the present study, patients with lower AAPR displayed poor prognosis, an observation that was consistent with the previous findings.

As a result of inflammation, oxidative stress produces reactive oxygen species that can damage protein, lipids, DNA, and facilitate the production of highly mutagenic metabolites[41]. Accordingly, oxidative stress plays a vital role in the tumorigenesis of PDAC[42]. Elevated ALP levels may serve as a potential predictor of oxidative stress[43], thereby contributing to cancer progression and poor disease outcomes[44][45]. Because of this, patients with low AAPR might have a poor prognosis.

Herein, we demonstrated the prognostic value of AAPR for unresectable PDAC by multivariate and univariate models as well as PSM analyses. Besides, patients' characteristics were well matched to minimize potential confounding bias. The prognostic value of AAPR was investigated in the entire cohort and further validated in the PSM cohort. Moreover, AAPR was confirmed to be associated with OS in most subgroups, which suggested that AAPR could be applied in patients with different clinicopathological features.

However, this study had a few limitations. First, our cohort was a retrospective cohort in a single center and composed of Chinese patients only; therefore, these results do not apply to other populations. Further multicenter prospective studies are thus recommended. Second, FOLFIRINOX is a standard regimen option for patients with metastasized PDAC. However, FOLFIRINOX is not widely used by Chinese patients because of its severe side effects. Whether AAPR could be used in patients receiving FOLFIRINOX remains unclear. Third, the underlying mechanism between the AAPR and cancer biology was not investigated and therefore needs further research.

\section{Conclusions}


In conclusion, our results suggest that pretreatment AAPR may serve as a prognostic predictor of overall survival in patients with unresectable PDAC. AAPR shows potential in improving the prediction performance of conventional prognostic model, which may help clinicians to identify patients at high risk and guide individualized treatment. Further prospective studies are needed to validate these results.

\section{Declarations}

Ethics approval and consent to participate

This study was approved by the Ethics Committee of Fudan University Shanghai Cancer Center. Written informed consent was obtained from each participant.

Consent for publication

Informed consent was obtained from all participants for publication.

Availability of data and materials

All data included in the present study were presented in the main manuscript.

Competing interests

The authors declare no competing interests.

Funding

This study was funded by the National Nature Science Foundation of China (NO. 81930115 and NO.81973616)

Authors' contributions

KZ: acquired data and wrote the manuscript, SD and YHJ: data acquisition, HFG, and LYC: quality control of data and data analysis, YQH: manuscript review, $\mathrm{HC}$ and ZC: study concept and design. The final manuscript was approved by all authors who agreed to be accountable for the content of this work.

Acknowledgements

We thank Xiu-Mei Zhang and Lu-Ming Liu for their contributions in patient follow-ups.

\section{References}

1. Siegel RL, Miller KD, Jemal A. Cancer statistics, 2019. CA Cancer J Clin. 2019;69:7-34.

2. Chen W, Zheng R, Baade PD, Zhang S, Zeng H, Bray F, et al. Cancer statistics in China, 2015. CA Cancer J Clin. 2016;66:115-32. 
3. Ryan DP, Hong TS, Bardeesy N. Pancreatic adenocarcinoma. N Engl J Med. 2014;371:1039-49.

4. Kamisawa T, Wood LD, Itoi T, Takaori K. Pancreatic cancer. Lancet. 2016;388:73-85.

5. Burris HA, Moore MJ, Andersen J, Green MR, Rothenberg ML, Modiano MR, et al. Improvements in survival and clinical benefit with gemcitabine as first-line therapy for patients with advanced pancreas cancer: a randomized trial. J Clin Oncol. 1997;15:2403-13.

doi:10.1200/JC0.1997.15.6.2403.

6. Conroy T, Desseigne F, Ychou M, Bouché O, Guimbaud R, Bécouarn Y, et al. FOLFIRINOX versus gemcitabine for metastatic pancreatic cancer. N Engl J Med. 2011;364:1817-25. doi:10.1056/NEJMoa1011923.

7. Von Hoff DD, Ervin T, Arena FP, Chiorean EG, Infante J, Moore M, et al. Increased survival in pancreatic cancer with nab-paclitaxel plus gemcitabine. N Engl J Med. 2013;369:1691-703. doi:10.1056/NEJMoa1304369.

8. Arroyo V, García-Martinez R, Salvatella X. Human serum albumin, systemic inflammation, and cirrhosis. J Hepatol. 2014;61:396-407. doi:10.1016/j.jhep.2014.04.012.

9. Millan JL. Alkaline Phosphatases: Structure, substrate specificity and functional relatedness to other members of a large superfamily of enzymes. Purinergic Signal. 2006;2:335-41.

10. Li X, Mortensen B, Rushfeldt C, Huseby NE. Serum gamma-glutamyltransferase and alkaline phosphatase during experimental liver metastases. Detection of tumour-specific isoforms and factors affecting their serum levels. Eur J Cancer. 1998;34:1935-40.

11. Dua P, Kang HS, Hong SM, Tsao MS, Kim S, Lee DK. Alkaline phosphatase ALPPL-2 is a novel pancreatic carcinoma-associated protein. Cancer Res. 2013;73:1934-45.

12. Mori K, Janisch F, Parizi MK, Mostafaei H, Lysenko I, Enikeev DV, et al. Prognostic value of alkaline phosphatase in hormone-sensitive prostate cancer: a systematic review and meta-analysis. Int $\mathrm{J}$ Clin Oncol. 2019. doi:10.1007/s10147-019-01578-9.

13. Chan AWH, Chan SL, Mo FKF, Wong GLH, Wong VWS, Cheung YS, et al. Albumin-to-alkaline phosphatase ratio: A novel prognostic index for hepatocellular carcinoma. Dis Markers. 2015;2015:564057. doi:10.1155/2015/564057.

14. Li S-J, Lv W-Y, Du H, Li Y-J, Zhang W-B, Che G-W, et al. Albumin-to-alkaline phosphatase ratio as a novel prognostic indicator for patients undergoing minimally invasive lung cancer surgery: Propensity score matching analysis using a prospective database. Int J Surg. 2019;69 April:32-42. doi:10.1016/j.ijsu.2019.07.008.

15. Nie $M$, Sun $P$, Chen $C$, Bi X, Wang $Y$, Yang $H$, et al. Albumin-to-Alkaline phosphatase ratio: A novel prognostic index of overall survival in cisplatin-based chemotherapy-treated patients with metastatic nasopharyngeal Carcinoma. J Cancer. 2017;8:809-15.

16. Xiong JP, Long JY, Xu WY, Bian J, Huang HC, Bai Y, et al. Albumin-to-alkaline phosphatase ratio: A novel prognostic index of overall survival in cholangiocarcinoma patients after surgery. World $\mathrm{J}$ Gastrointest Oncol. 2019;11:39-47. 
17. Tan P, Xie N, Ai J, Xu H, Xu H, Liu L, et al. The prognostic significance of Albumin-to-Alkaline Phosphatase Ratio in upper tract urothelial carcinoma. Sci Rep. 2018;8:1-8.

18. Xia A, Chen Y, Chen J, Pan Y, Bao L, Gao X. Prognostic value of the albumin-to-alkaline phosphatase ratio on urologic outcomes in patients with non-metastatic renal cell carcinoma following curative nephrectomy. J Cancer. 2019;10:5494-503.

19. Zhang C, Li Y, Ji R, Zhang W, Zhang C, Dan Y, et al. The prognostic significance of pretreatment albumin/alkaline phosphatase ratio in patients with stage ib-iia cervical cancer. Onco Targets Ther. 2019;12:9559-68.

20. Pu N, Gao S, Xu Y, Zhao G, Lv Y, Nuerxiati A, et al. Alkaline phosphatase-to-albumin ratio as a prognostic indicator in pancreatic ductal adenocarcinoma after curative resection. $\mathrm{J}$ Cancer. 2017;8:3362-70.

21. Amin MB, Greene FL, Edge SB, Compton CC, Gershenwald JE, Brookland RK, et al. The Eighth Edition AJCC Cancer Staging Manual: Continuing to build a bridge from a population-based to a more "personalized" approach to cancer staging. CA Cancer J Clin. 2017;67:93-9. doi:10.3322/caac.21388.

22. Camp RL, Dolled-Filhart M, Rimm DL. X-tile: A new bio-informatics tool for biomarker assessment and outcome-based cut-point optimization. Clin Cancer Res. 2004;10:7252-9.

23. Benedetto U, Head SJ, Angelini GD, Blackstone EH. Statistical primer: Propensity score matching and its alternatives. Eur J Cardio-thoracic Surg. 2018;53:1112-7.

24. Akaike H. Information Theory and an Extension of the Maximum Likelihood Principle. In: Parzen E, Tanabe K, Kitagawa G, editors. Selected Papers of Hirotugu Akaike. New York: Springer New York; 1998. pp. 199-213. doi:10.1007/978-1-4612-1694-0_15.

25. Uno H, Cai T, Pencina MJ, D'Agostino RB, Wei LJ. On the C-statistics for evaluating overall adequacy of risk prediction procedures with censored survival data. Stat Med. 2011;30:1105-17.

26. Chan AWH, Chan SL, Mo FKF, Wong GLH, Wong VWS, Cheung YS, et al. Albumin-to-alkaline phosphatase ratio: A novel prognostic index for hepatocellular carcinoma. Dis Markers. 2015;2015.

27. Hanahan D, Weinberg RA. Hallmarks of cancer: the next generation. Cell. 2011;144:646-74.

28. Mendez CM, McClain CJ, Marsano LS. Albumin therapy in clinical practice. Nutr Clin Pract. 2005;20:314-20.

29. Coussens LM, Werb Z. Inflammation and cancer. Nature. 2002;420:860-7.

30. Garcia-Martinez R, Andreola F, Mehta G, Poulton K, Oria M, Jover M, et al. Immunomodulatory and antioxidant function of albumin stabilises the endothelium and improves survival in a rodent model of chronic liver failure. J Hepatol. 2015;62:799-806.

31. Nojiri S, Joh T. Albumin suppresses human hepatocellular carcinoma proliferation and the cell cycle. Int J Mol Sci. 2014;15:5163-74.

32. Bağırsakçı E, Şahin E, Atabey N, Erdal E, Guerra V, Carr BI. Role of Albumin in Growth Inhibition in Hepatocellular Carcinoma. Oncology. 2017;93:136-42. doi:10.1159/000471807. 
33. Yang J-R, Xu J-Y, Chen G-C, Yu N, Yang J, Zeng D-X, et al. Post-diagnostic C-reactive protein and albumin predict survival in Chinese patients with non-small cell lung cancer: a prospective cohort study. Sci Rep. 2019;9:8143.

34. Lis CG, Grutsch JF, Vashi PG, Lammersfeld CA. Is serum albumin an independent predictor of survival in patients with breast cancer? JPEN J Parenter Enteral Nutr. 2003;27:10-5.

35. Onate-Ocana LF, Aiello-Crocifoglio V, Gallardo-Rincon D, Herrera-Goepfert R, Brom-Valladares R, Carrillo JF, et al. Serum albumin as a significant prognostic factor for patients with gastric carcinoma. Ann Surg Oncol. 2007;14:381-9.

36. Hirschhaeuser F, Sattler UGA, Mueller-Klieser W. Lactate. A metabolic key player in cancer. Cancer Res. 2011;71:6921-5.

37. Yamamoto K, Awogi T, Okuyama K, Takahashi N. Nuclear localization of alkaline phosphatase in cultured human cancer cells. Med Electron Microsc. 2003;36:47-51.

38. Rao SR, Snaith AE, Marino D, Cheng X, Lwin ST, Orriss IR, et al. Tumour-derived alkaline phosphatase regulates tumour growth, epithelial plasticity and disease-free survival in metastatic prostate cancer. Br J Cancer. 2017;116:227-36.

39. Chen XY, Lan M, Zhou Y, Chen WZ, Hu D, Liu JM, et al. Risk factors for bone metastasis from renal cell cancer. J Bone Oncol. 2017;9 August:29-33.

40. Zhang L, Gong Z. Clinical Characteristics and Prognostic Factors in Bone Metastases from Lung Cancer. Med Sci Monit. 2017;23:4087-94.

41. Sies H. Oxidative stress: a concept in redox biology and medicine. Redox Biol. 2015;4:180-3.

42. Martinez-Useros J, Li W, Cabeza-Morales M, Garcia-Foncillas J. Oxidative Stress: A New Target for Pancreatic Cancer Prognosis and Treatment. J Clin Med. 2017;6.

43. Lopez-Posadas R, Gonzalez R, Ballester I, Martinez-Moya P, Romero-Calvo I, Suarez MD, et al. Tissuenonspecific alkaline phosphatase is activated in enterocytes by oxidative stress via changes in glycosylation. Inflamm Bowel Dis. 2011;17:543-56.

44. Carr BI, Guerra V. Hepatocellular Carcinoma Extrahepatic Metastasis in Relation to Tumor Size and Alkaline Phosphatase Levels. Oncology. 2016;90:136-42.

45. Kim SH, Song MK, Joung JY, Chung J, Lee KH, Seo HK. Significant clinicopathologic prognostic factors for bladder recurrence, progression, and cancerspecific survival after surgery among patients with upper urinary tract urothelial carcinoma. Investig Clin Urol. 2019;60:432-42.

\section{Figures}



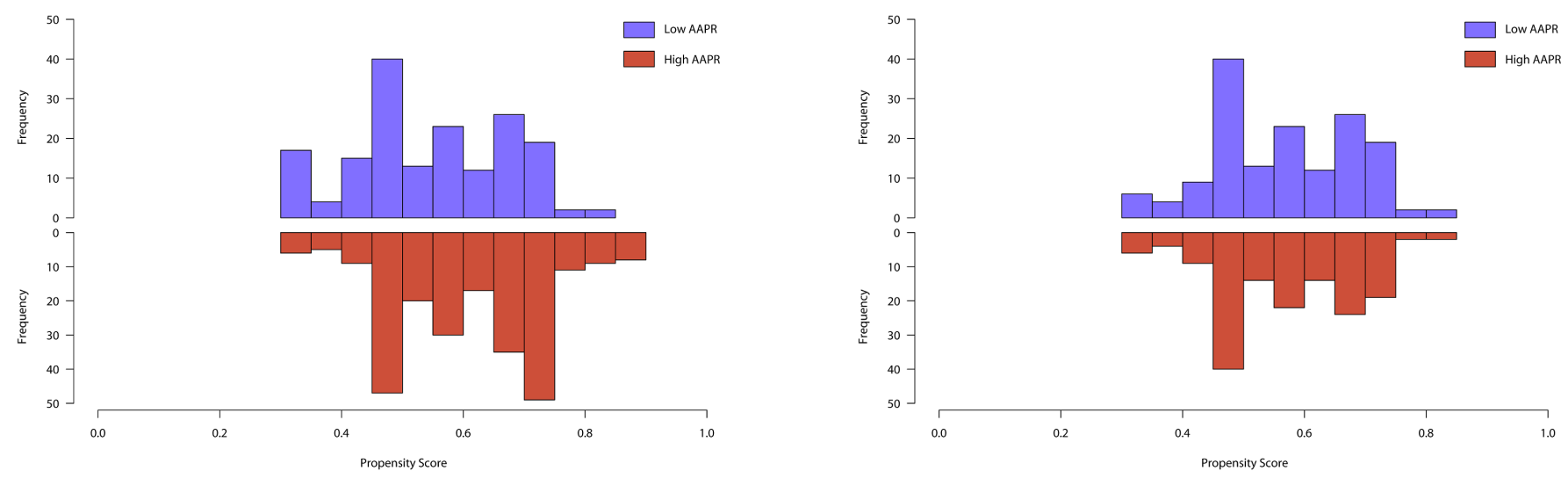

Figure 1

Mirrored histogram showing distribution and overlapping of propensity score between low and high AAPR groups in unmatched $(A)$ and matched $(B)$ cases.

(A)

Entire Cohort

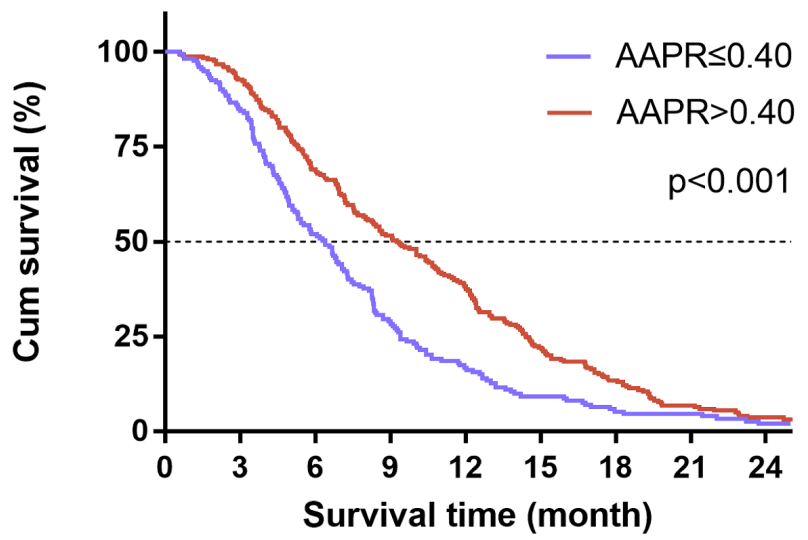

(B)

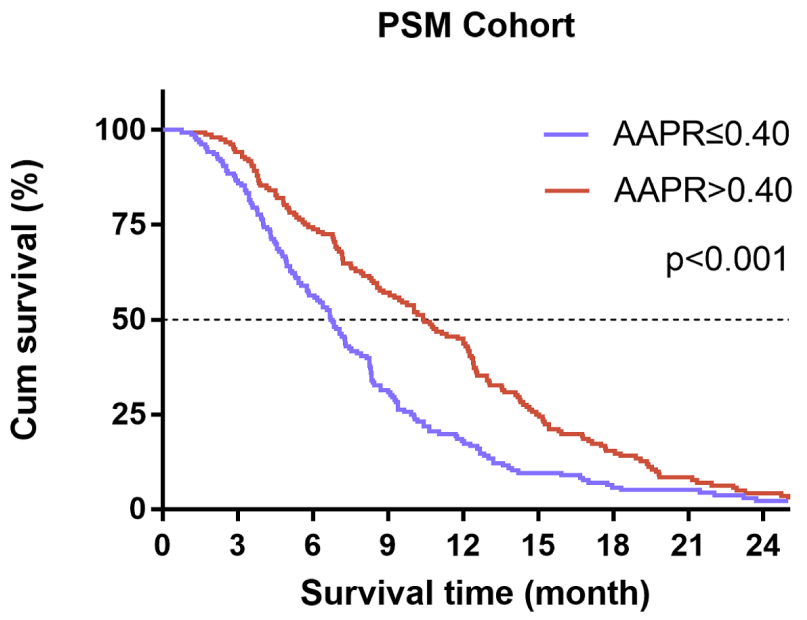

Figure 2

Kaplan-Meier survival curves for OS of subjects with unresectable PDAC based on AAPR levels in the entire cohort (A) and PSM cohort (B). 
Subgroup

Harzard Ratio

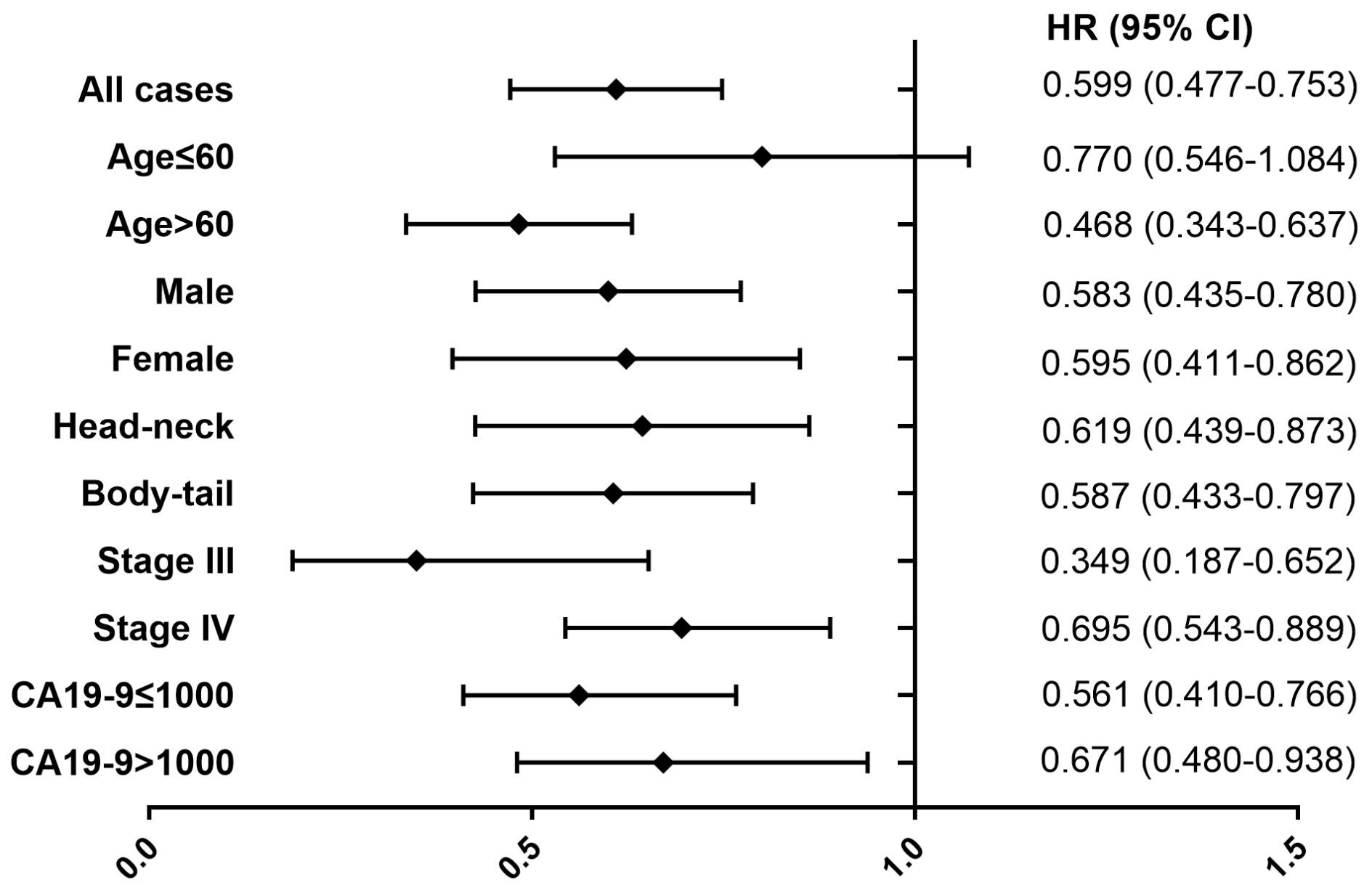

Figure 3

Subgroup analyses of the predictive value of AAPR for overall survival. Hazard ratios (HR) of AAPR levels were calculated for overall survival in different patient subgroups in the PSM cohort. 